\title{
Prevention of episodic migraines with topiramate: results from a non-interventional study in a general practice setting
}

\author{
Gereon Nelles • Lukas Schmitt • Thomas Humbert • Veit Becker • \\ Petra Sandow $\cdot$ Karin Bornhoevd · Dirk Fritzsche - Barbara Schäuble · \\ on behalf of the TOPMATMIG-0001 investigators
}

Received: 16 August 2009/ Accepted: 28 September 2009/Published online: 6 November 2009

(C) Springer-Verlag 2009

\begin{abstract}
The majority of patients with migraine headaches are treated in non-specialized institutions though data on treatment outcomes are largely derived from tertiary care centers. The current non-interventional study explores efficacy and tolerability outcomes of patients with episodic migraines receiving topiramate as preventive agent in a general practice setting. A total of 366 patients ( $87 \%$ female, mean age $41.8 \pm 11.6$ years) were eligible for migraine prevention and treated with flexible dose topiramate for 6 months (core phase), and optionally for a total of 12 months (follow-up phase). Overall, 261 patients (77.7\% of safety analysis set, SAF) completed the core phase. Reasons for discontinuation
\end{abstract}

G. Nelles

Neurology Outpatient Clinic, St. Elisabeth Krankenhaus Köln, 50935 Cologne, Germany

L. Schmitt

Gesundheitshaus Karl Schneider Passagen, Heussweg 37,

20255 Hamburg-Eimsbuettel, Germany

T. Humbert · V. Becker

Private Practice, Kümmellstr. 1, 20249 Hamburg, Germany

P. Sandow

Private Practice, Reichsstraße 81, 14052 Charlottenburg,

Berlin, Germany

K. Bornhoevd · B. Schäuble

Janssen-Cilag EMEA, Johnson and Johnson Platz 1,

41470 Neuss, Germany

D. Fritzsche

MEDIDATA GmbH, Max-Stromeyer-Street 166,

78467 Constance, Germany

G. Nelles ( $\square)$

Neurologische Praxis, St. Elisabeth Krankenhaus,

Werthmannstrasse 1c, 50935 Köln, Germany

e-mail: gereon.nelles@uni-duisburg-essen.de included adverse events (2.1\%), lost to follow-up (1.8\%), other reasons $(1.5 \%)$, and end of therapy $(0.3 \%)$ though in the majority of patients who discontinued no reasons were listed. The median daily dose at endpoint was $50 \mathrm{mg} /$ day (range, $25-187.5 \mathrm{mg} /$ day). The median days with migraine headaches decreased from 6.0 to 1.2 days $(p<0.001)$, median pain intensity score decreased from 17.0 to 3.2 points $(p<0.001)$. In women with reported menstruation-associated migraine, the median number of migraine attacks decreased from 4.0 to $0.9(p<0.001)$. Absenteeism as well as triptan use decreased significantly, and significant improvements in activities of daily living and quality of life were reported. The most frequently reported AEs were paraesthesia (4.2\%) and nausea (3\%). Results suggest that migraine prevention with topiramate in a general practice is generally well tolerated and associated with a significant improvement in migraine headaches and related functional impairment.

Keywords Migraine prevention - Topiramate · Open label study $\cdot$ Menstruation

$\begin{array}{ll}\text { Abbreviations } \\ \text { AE } & \text { Adverse event } \\ \text { CRF } & \text { Case report form } \\ \text { CP } & \text { Core phase } \\ \text { EAS } & \text { Efficacy analysis set } \\ \text { FUAS } & \text { Follow up analysis set } \\ \text { EFF } & \text { Efficacy population } \\ \text { HIT } & \text { Headache impact test } \\ \text { IHS } & \text { International headache society } \\ \text { IQR } & \text { Interquartile range } \\ \text { LOCF } & \text { Last observation carried forward } \\ \text { SAF } & \text { Safety population } \\ \text { SD } & \text { Standard deviation }\end{array}$




\section{Introduction}

Migraine is a common neurological disorder affecting approximately 12 to $14 \%$ of all women and 6 to $8 \%$ of all men in western societies $[1,2]$. It is reported that $43 \%$ of women and $18 \%$ of men suffer from migraine at some point in their lives [3, 4]. Due to the negative impact on quality of life, daily activity and work-related productivity, timely diagnosis, and effective management of the patient is important [5-7]. Next to non-pharmacological interventions, effective acute and preventive treatments play an important role [8]. Migraine prevention not only reduces the frequency, severity, and duration of attacks, but was shown to reduce migraine-related socio-economic burden [9]. Pharmacological prevention of migraine is recommended by several professional societies if patients fulfill criteria for preventive treatment [10]. Multiple effective drugs are available, however, they differ in the level of scientific evidence to support their use in migraine prevention as well as in their clinical profile. Preventive medication frequently used and recommended by professional bodies include beta-blockers, calcium channel blockers, tricyclic antidepressants, or antiepileptic drugs, such as valproate and topiramate [11-16]. Topiramate is a fructopyranose sulfamate with proven efficacy in migraine prevention. This was demonstrated in several randomized, controlled clinical trials [12, 13, 18]. Most commonly, treatments are used in monotherapy, however, there is some emerging data that in certain individuals add-on therapy might be appropriate [17].

Despite considerable burden of disease and available class I evidence, only 1 in 5 patients who fulfill the criteria for preventive migraine therapy are treated and considerable underrecognition of the disease itself is reported [19].

Though general practitioners play an important role in disease recognition and initial treatment [20], there are only few data on patient outcomes with topiramate derived from non-specialized centers [21]. Therefore, the present study is designed to explore tolerability and efficacy outcomes in outpatients treated with topiramate for migraine prevention in a naturalistic setting.

\section{Methods}

\section{Study design}

This was a prospective, multicenter non-interventional study carried out between February 2006 and December 2007 in Germany. Patients were followed-up during a 6 months core phase with an optional follow-up for up to 12 months in total. The decision to extend the treatment period from 6 to 12 months was based on physicians' and patients' assessments of therapy at month 6 . No formal criteria were established. Patients were evaluated at baseline, after approximately 2, 4, 8, 12 weeks, and after 6 months with optional follow-up after 9 and 12 months. Patients' demographics, disease characteristics including frequency of migraine attacks, migraine auras and associated symptoms, pain intensity, quality of life, absenteeism, previous and currently used preventive agents, type and frequency of intake of acute medication, other concomitant medication, and adverse events (AEs) were recorded in the electronic case report form (CRF). Data on frequency, severity, and symptoms of all headaches or auras, and the use of acute medications were based on patient's diaries, which were transcribed by the investigator into the patient's CRF. All visits were office-based exception except for Visit 2 (2 weeks) and Visit 4 (8 weeks), which were optional and by phone.

\section{Patient selection}

Patients were selected from 183 non-academic neurology, anesthesiology, or general practices in Germany. Patients, aged 18 years and older were documented if they carried a diagnosis of episodic migraine headaches and their diagnosis was based on the International Headache Society (IHS) criteria http://www.i-h-s.org/upload/ct_clas/ihc_II_ main_no_print.pdf. The patients were prospectively followed-up for 6 and optionally for 12 months if migraine preventive therapy was indicated based on guidelines published by the German Neurological Society (DGN) http://www.ehf-org.org/Documents/Germany.pdf and the German Society for Headache (DGKM) [10]. Migraine headache, migraine attacks, and auras were defined based on the IHS definitions. Patients with known hypersensitivity or other contraindications prohibiting topiramate therapy were excluded from participation.

\section{Treatment}

Topiramate (Topamax ${ }^{\circledR}$ Migräne; Janssen-Cilag GmbH, Germany) was recommended to be taken based on the summary of product characteristics. Titration rate and final dose were guided by the patient's clinical response to topiramate therapy.

\section{Concomitant therapies}

Patients were allowed to take acute rescue medications, such as analgesics, non-steroidal anti-inflammatory drugs, triptans, ergotamine derivatives, opioids, and other rescue medication during any phase in the study. The use of acute rescue medication had to be recorded in the patient diary together with disease-related information (e.g. migraine attack information). 
Ethics

The study was conducted in accordance with the "Empfehlungen zur Planung, Durchführung und Auswertung von Anwendungsbeobachtungen (Recommendation for the planning, implementation and evaluation of non-interventional studies with medicinal products)" of the BfArM (Federal Institute for Drugs and Medical Devices) dated 12 November 1998 and the "Notice to Marketing Authorisation Holders-Pharmacovigilance Guidelines" issued by the EMEA (European Agency for the Evaluation of Medicinal Products). Janssen-Cilag has notified the BfArM about the conduct of the study. An independent ethics committee (Freiburg, Germany) evaluated the study protocol and granted approval for study conduct.

\section{Outcome measures}

The primary objective of the study was to explore efficacy and tolerability outcomes of flexibly dosed topiramate in routine clinical practice. Exploratory efficacy outcome measures included the change in the median number of monthly migraine attacks from baseline to the last visit of the core phase (6 months) and to the last visit of the optional follow-up phase (for a maximum of 12). In addition, changes in monthly migraine days, changes in frequency of migraine attacks, changes in pain intensity score were captured; the percentage of patients with $\geq 50 \%$, $\geq 75 \%$, and $\geq 90 \%$ reduction in the mean number of monthly migraine attacks (categorical responder rates). Types and frequencies of AEs, the dosage of topiramate in daily practice, and the impact of migraine on activities of daily living and on the quality of life (HIT- $6^{\mathrm{TM}}$ ) were analyzed. Impairment of daily life was measured with the impairment score. The impairment score was calculated as (days with severe impairment $\times 3)+($ days with moderate impairment $\times$ $2)+$ (days with slight impairment $\times 1$ ), normalized to 28 days. The HIT- $6^{\text {TM }}$ is a tool to measure the impact of headaches on daily life. The questionnaire consists of 6 questions with a 5-point scale ("never", "rarely", "sometimes", "very often", and "always"). The sum of the total score ranges between 36 (no impact) and 78 (severe impact).

Statistical analyses and data management

\section{Statistics}

All statistical tests were exploratory. No adjustment for multiple testing was performed. Last observation carried forward (LOCF) analyses were performed for treatment effect parameters using the last available post-dose value of the respective parameter as the endpoint of analysis. No other imputation of data was performed. Continuous variables were described by the total number of observations $(N)$, minimum, maximum, mean, standard deviation (SD), median, and interquartile range (IQR). Categorical variables were described by the total number of patients, and by the number and the proportion of patients for each category. Changes from baseline were analyzed by exploratory Wilcoxon signed rank tests (significance level: 0.05). Data regarding AEs, previous and concomitant diseases, and surgical procedures were coded using Medical Dictionary for Regulatory Activities (MedDRA) version 10.1. The incidence of AEs was computed together with its binomial $95 \%$ confidence interval.

\section{Data sets analyzed}

Available data of all patients were listed in patient data listings. For analysis, the following populations were defined: a Safety population (SAF), which included all patients for whom documentation was started and for whom the intake of at least one dose of topiramate was documented, and a Treatment effect population (EFF), which included all SAF patients for whom at least one treatment effect variable was documented after the start of topiramate treatment. In addition, a subanalyses was stipulated to compare women with menstruation-associated migraine at baseline versus women with migraines not associated with menstruation at baseline. An overview on the study populations is given in Fig. 1.

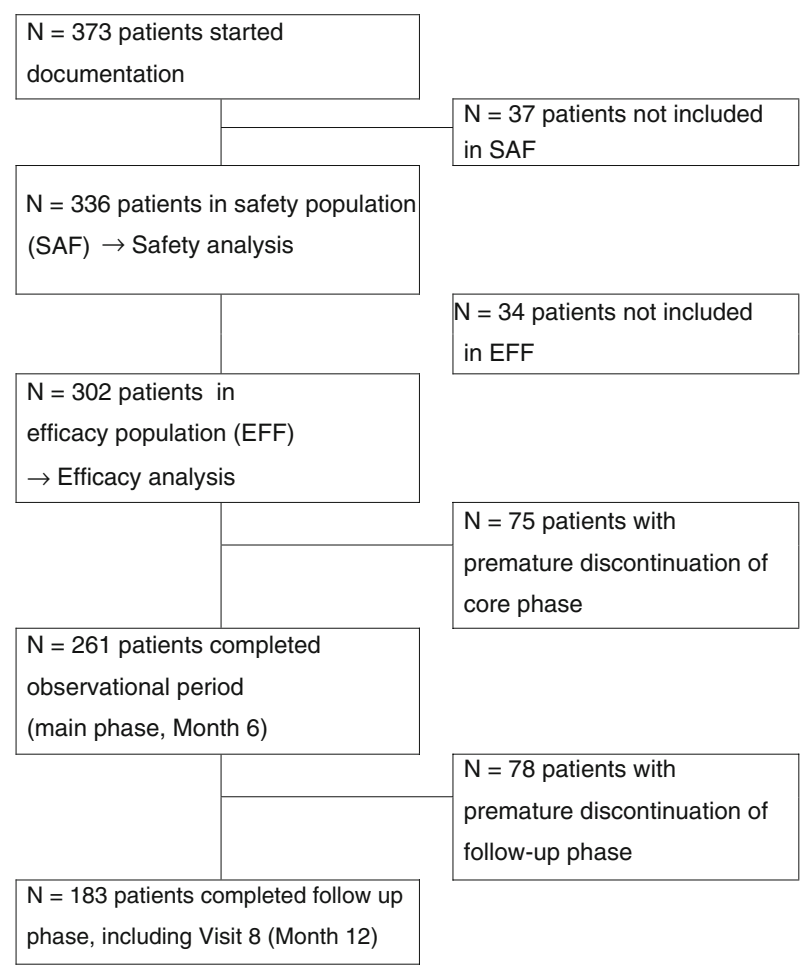

Fig. 1 Flowchart showing an overview on the study population 


\section{Results}

A total of 336 out of 373 patients evaluated received topiramate (SAF). In 34 patients, no post-baseline efficacy outcomes data were documented. Based on this, the EFFanalysis comprised 302 patients (Fig. 1). A total of 261 patients $(77.7 \%$ of SAF) completed the 6 months observational period (core phase), whereas 75 patients $(22.3 \%$ of SAF) discontinued prematurely. Reasons for premature discontinuation were: AEs $(N=7,2.1 \%$ of SAF), lost to follow-up $(N=6,1.8 \%)$, other reasons $(N=5,1.5 \%)$, and end of therapy $(N=1,0.3 \%)$. In the majority of patients though, a reason for discontinuation was not obtainable. A total of 203 patients $(60.4 \%$ of SAF) had data available at Visit 7 (Month 9) and 183 patients (54.5\% of SAF) completed the 12 months.

Baseline demographics, disease characteristics, and previous treatment

Pertinent baseline data and disease characteristics of the 302 patients treated in the core phase (ITT-analysis) are summarized in Tables 1 and 2. As much as 29.5\% of patients reported migraine headaches with auras and in $36.8 \%$ of women menstruation-associated migraines were reported.

In the EFF, 139 patients (46.0\% of EFF) had received migraine preventive treatment in the past (Table 3). As much as $82.7 \%(N=115)$ had been exposed to 1 or 2 therapeutic attempts with beta blockers and $5.0 \%$ even to 3

Table 1 Demographic data

\begin{tabular}{lll}
\hline & SAF & EFF \\
& $N=336$ & $N=302$ \\
\hline Gender $(N, \%)$ & & \\
Female & $292(76.9)$ & $266(88.1)$ \\
Male & $44(13.1)$ & $36(11.9)$ \\
Age (years) & & $41.5 \pm 11.4$ \\
Mean \pm SD & $41.8 \pm 11.6$ & $42(18,71)$ \\
Median (range) & $42(18,71)$ & $168.5 \pm 7.0$ \\
Height (cm) & & $168(150,193)$ \\
Mean \pm SD & $168.6 \pm 7.1$ & $68.6 \pm 11.3$ \\
Median (range) & $168(150,193)$ & $67(46,107)$ \\
Weight (kg) & & \\
Mean \pm SD & $69.1 \pm 11.6$ & $24.2 \pm 3.6$ \\
Median (range) & $68(46,110)$ & $23.4(17.7,38.2)$ \\
BMI (kg/m $\left.{ }^{2}\right)$ & & \\
Mean \pm SD & $24.3 \pm 3.7$ & \\
Median (range) & $23.5(17.7,41.3)$ & \\
\hline
\end{tabular}

Percentages relate to the number of patients in the respective population
Table 2 Disease characteristics

\begin{tabular}{|c|c|c|}
\hline & $\begin{array}{l}\text { SAF } \\
N=336\end{array}$ & $\begin{array}{l}\mathrm{EFF} \\
N=302\end{array}$ \\
\hline \multicolumn{3}{|c|}{ Age at first diagnosis of migraine (years) } \\
\hline$N$ & 328 & 295 \\
\hline Mean $\pm \mathrm{SD}$ & $24.1 \pm 9.0$ & $24.0 \pm 8.6$ \\
\hline Median (range) & $22(8,53)$ & $22(8,53)$ \\
\hline \multicolumn{3}{|c|}{ Time since diagnosis (years) } \\
\hline $\mathrm{N}$ & 328 & 295 \\
\hline Mean $\pm \mathrm{SD}$ & $17.5 \pm 11.0$ & $17.4 \pm 10.7$ \\
\hline Median (range) & $17(0,52)$ & $17(0,52)$ \\
\hline \multicolumn{3}{|c|}{ Migraine associated with menstruation (women only) $\left(N, \%^{\mathrm{a}}\right)$} \\
\hline No & $183(62.7)$ & $167(62.8)$ \\
\hline Yes & $107(36.6)$ & $98(36.8)$ \\
\hline \multicolumn{3}{|l|}{ Aura $\left(N, \%^{\mathrm{b}}\right)$} \\
\hline No & $234(69.6)$ & $213(70.5)$ \\
\hline Yes & $102(30.4)$ & $89(29.5)$ \\
\hline
\end{tabular}

to 4 attempts. Antidepressants were used at least once by 43 patients (30.9\% of pretreated EFF patients). As much as 37 patients $(26.6 \%)$ used $\mathrm{Ca}^{2+}$-channel blockers and 23 patients $(16.5 \%)$ used anticonvulsant drugs other than topiramate at least once (Table 3). At baseline, a total of 20 patients $(6.6 \%$ of $302 \mathrm{EFF}$ patients) received preventive migraine treatment other than topiramate. The treatment with these drugs continued during the study phase. Due to the low number of patients, no subanalyses was added.

Topiramate dose

At baseline, the majority of patients $(N=259,85.8 \%$ of 302 EFF patients) started on the recommended daily dose of $25 \mathrm{mg}$; 33 patients (10.9\% of EFF) started with $50 \mathrm{mg}, 6$ patients $(2.0 \%)$ started on $100 \mathrm{mg}$, and $3(1.0 \%)$ patients started on $200 \mathrm{mg}$. One patient had an initial dose of $12.5 \mathrm{mg} /$ day. After 6 months of treatment $(N=261)$, $44.4 \%$ of patients took a total daily dose of $50 \mathrm{mg}, 24.9 \%$ took $100 \mathrm{mg} / \mathrm{day}$, and $13.0 \%$ took $75 \mathrm{mg} / \mathrm{d}$. The mean daily dose was $58.7 \pm 27.4 \mathrm{mg} /$ day at endpoint.

\section{Efficacy outcomes}

Number of migraine attacks

The median (IQR) number of migraine attacks per month declined gradually from $4.0(3.0-6.0)$ at baseline to 0.9 (0.4-1.8) after 6 months of treatment (Fig. 2a). At the 12month visit, a further slight improvement was documented. 
Table 3 Frequency and type of previous migraine prevention in EFF population $(N=302)$

\begin{tabular}{lllll}
\hline Patients with preventive treatment & $139(46.0)$ & & & \\
Number of therapeutic trials/drugs used & $1-2$ & $3-4$ & $5-10$ & $>10$ \\
Beta blockers & $115(82.7)$ & $7(5.0)$ & $1(0.7)$ & $1(0.7)$ \\
$\mathrm{Ca}^{2+}$-channel blockers & $37(26.6)$ & & & $1(0.7)$ \\
Anticonvulsants & $23(16.5)$ & & & \\
Antidepressives & $43(30.9)$ & $2(1.4)$ & $1(0.7)$ \\
Other & $14(10.1)$ & $3(2.2)$ & $1(0.7)$ \\
\hline
\end{tabular}

Fig. 2 (a) Number of migraine attacks. (b) Number of days with migraine. Asterisk Number of attacks and days were normalized to a period of 28 days
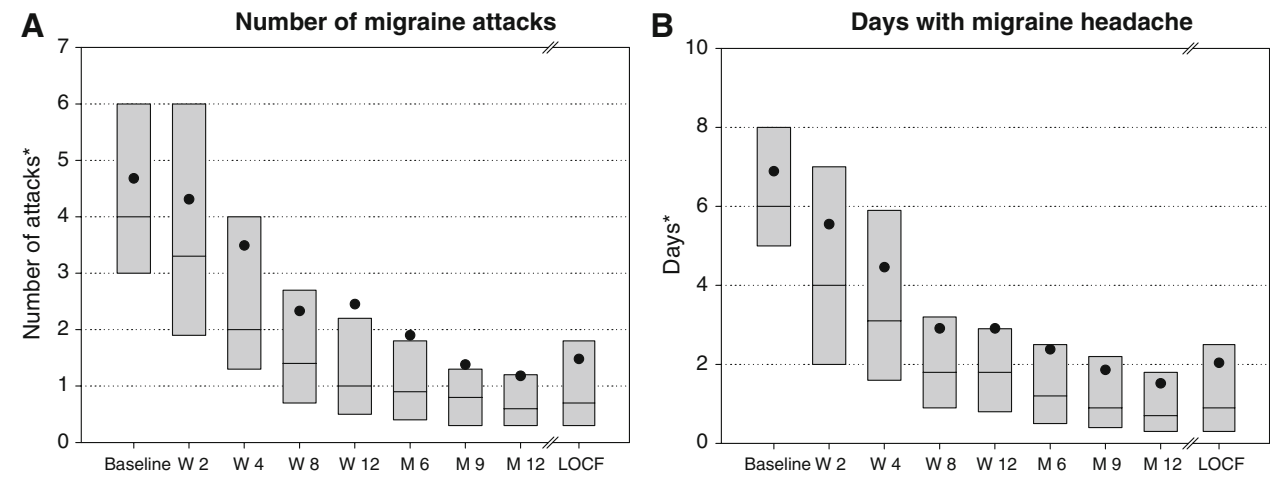

- $\begin{aligned} & \text { Q1 to Q3 with median } \\ & \text { mean }\end{aligned}$
In the overall population, the number of migraine attacks decreased to $0.8(0.3-2.0)$ at endpoint. The reduction in migraine attacks was statistically significant compared to baseline at all visits and for the ITT population.

\section{Number of days with migraine}

The median (IQR) number of migraine days decreased from 6.0 (5.0-8.0) days at baseline to $1.2(0.5-2.5)$ days at month 6 (Fig. 2b). At the end of the follow-up period (month 12), the median (IQR) for migraine days was 0.7 (0.3-1.8) and 0.9 days (0.4-2.7) in the ITT population. The reduction in the number of migraine days was statistically significant compared to baseline $(p<0.001)$ at all visits and for the ITT population. Six patients were identified who had 15 or more migraine days during their baseline. Due to the small number, no further analyses were done.

\section{Responder rates}

Migraine attacks were reduced by at least $50 \%$ in $28.1 \%$ of patients (i.e. 85 out of 302 patients) after 2 weeks of treatment with topiramate and by at least $75.9 \%$ at end of core phase (6 months). Outcomes remained stable during the follow-up phase (month 9: $80.8 \%$, month 12: 79.2\%). Results were similar in the ITT population. Here, $76.8 \%$ achieved at least 50\% reduction in migraine attacks (Fig. 3).

A clinically relevant proportion of patients achieved complete freedom of migraine headaches (100\% reduction). The percentage increased from $13.9 \%$ after 2 weeks to
Fig. 3 Responder rates for the number of migraine attacks and the mean number of days with migraine. Percentages relate to the number of patients with documented visits. Responder rates for days with migraine headache are not described in the text
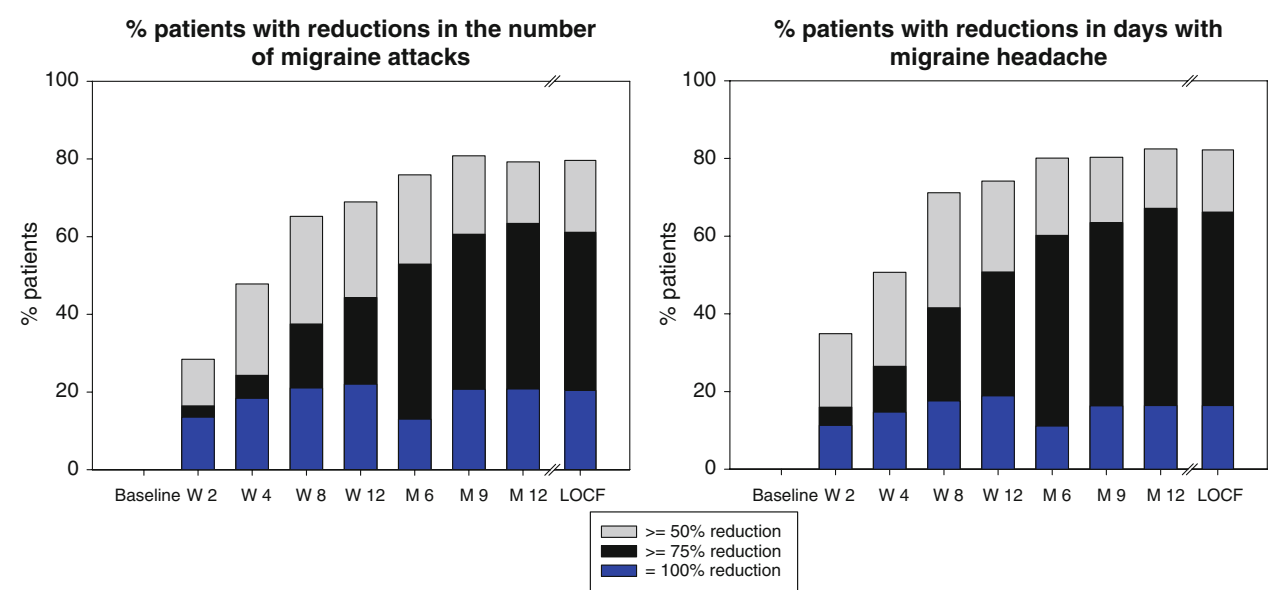
$18.2 \%, 21.6 \%$, and $22.1 \%$ after 4,8 , and 12 weeks. At the two follow-up visits, the proportion of patients with $100 \%$ reduction in migraine attacks reached approximately $21 \%$ (month 9: 20.7\%, month 12: 20.8\%). The calculated LOCF was $21.2 \%$.

\section{Pain intensity scores}

Figure 4 illustrates the decrease in the pain intensity score results in the course of the study period. The median (IQR) migraine intensity score decreased in patients with remaining migraine over time. At baseline, a score of 17.0 (12.0-24.0) points was calculated in 294 patients, declining to $12.0(7.5-19.4)$ points at week $2(N=257), 4.6(2.8-$ 9.3) points at week $8(N=224)$, and $3.2(1.5-6.2)$ points at month $6(N=228)$. During follow-up, further decrease was noted with the lowest value of 2.0 (1.0-5.0) points achieved at month $12(N=142)$. The median (IQR) LOCF was $2.6(1.3-7.0)$ points $(N=298)$. Changes from baseline were statistically significant $(p<0.001)$ at all visits as well as for the ITT population.

\section{Migraine with aura}

At baseline, 81 out of 302 patients $(26.8 \%$ ) reported migraine with aura, 215 patients $(71.2 \%)$ had no aura, and data were missing for 6 patients (2.0\%). During the course of study, the proportion of patients with reported aura decreased. At month 6, only 17 patients $(6.5 \%)$ and at month 12 , only 12 patients $(6.6 \%)$ reported migraine with aura.

\section{Migraine and menstruation}

A subanalyses explored efficacy outcomes in women with and without menstruation associated migraines. Results are based on women's reportings. A distinction between menstruation related migraines (MRM) and pure menstrual migraines (PMM) was not applied [22].
In women without MRM, the median (IQR) monthly number of migraine attacks was 4.0 (3.0-6.0) at baseline $(N=167)$. The median values decreased to $3.7(2.0-6.0)$ at week $2(N=163)$ and decreased further to $0.9(0.4-2.0)$ at month $6(N=147)$, and $0.6(0.3-1.2)$ at month 12 $(N=95)$. The median LOCF was $0.7(0.3-2.0 ; N=167)$. Changes from baseline were statistically significant $(p \leq 0.002)$ at all visits and for the ITT population.

In women with MRM, baseline migraine attack frequency as well as treatment response were similar. The median (IQR) monthly number of migraine attacks was 4.0 (3.0-6.0) at baseline $(N=96)$ and decreased to $2.8(1.8-$ $6.0)$ at week $2(N=96)$, to $0.9(0.3-1.6)$ at month 6 $(N=80)$, and $0.6(0.0-1.5)$ at month $12(N=59)$. The median LOCF was $0.8(0.3-2.0 ; N=98)$. Changes from baseline were statistically significant $(p \leq 0.024)$ at all visits and for the ITT population (Table 4).

\section{Impairment of activities in daily life}

The impairment of daily life is illustrated in Fig. 5. The median (IQR) impairment score decreased from 16.0 (12.0-23.0) points at baseline $(N=294)$ to $2.1(0.7-4.7)$ points at month $6(N=258)$, and further to $1.3(0.3-3.3)$ points at month $12(N=172)$. The median LOCF was 1.7 $(0.3-5.3 ; N=301)$. The changes from baseline were statistically significant $(p<0.001)$ at all visits and for the ITT population.

\section{Absenteeism}

The mean number of days decreased from $2.1 \pm 2.4$ days at baseline $(N=298)$ to $1.2 \pm 2.6$ days at week 2 $(N=296), 0.3 \pm 0.6$ days at month $6(N=257)$, and $0.1 \pm 0.3$ days at month $12(N=172)$. Mean LOCF was $0.3 \pm 1.0$ days $(N=302)$. The changes from baseline were statistically significant $(p<0.001)$ at all visits and for the LOCF.
Fig. 4 Intensity of migraine and other headache in patients with remaining headache. Asterisk Intensity score $=$ (days with severe

headache $\times 3)+($ days with moderate

headache $\times 2)+$ (days with slight headache $\times 1$ )
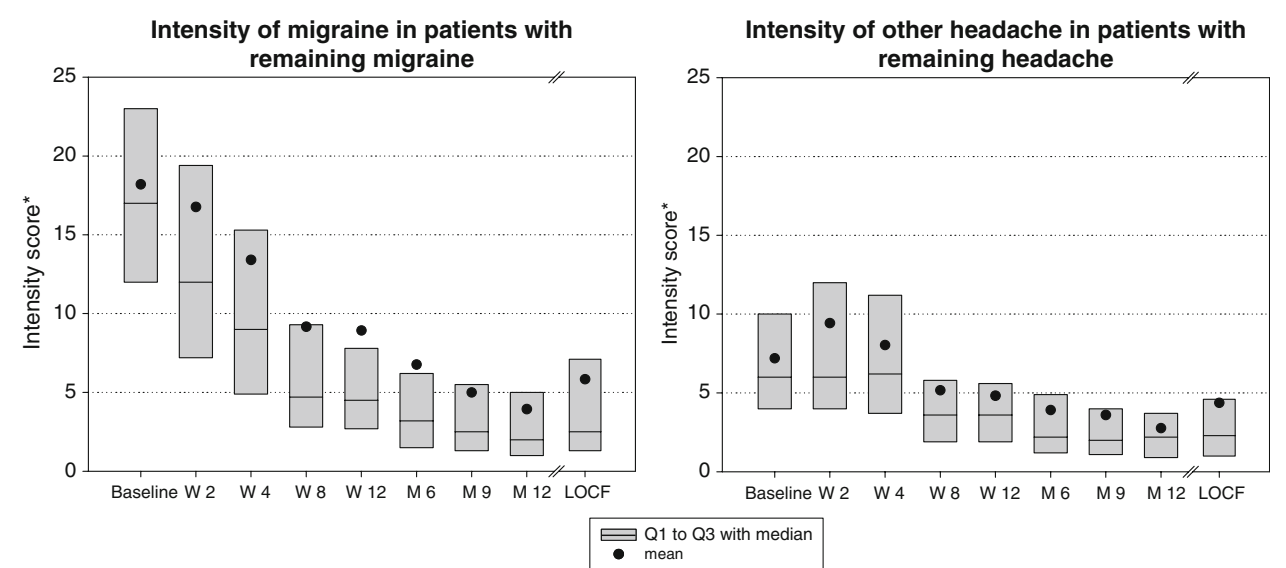
Table 4 Migraine associated with menstruation

\begin{tabular}{|c|c|c|c|c|c|c|}
\hline & $\begin{array}{l}\text { Baseline } \\
N=302\end{array}$ & $\begin{array}{l}\text { Week } 12 \\
N=272\end{array}$ & $\begin{array}{l}\text { Month } 6 \\
N=261\end{array}$ & $\begin{array}{l}\text { Month } 9 \\
N=203\end{array}$ & $\begin{array}{l}\text { Month } 12 \\
N=183\end{array}$ & $\begin{array}{l}\mathrm{LOCF} \\
N=235\end{array}$ \\
\hline \multicolumn{7}{|l|}{ Patients $N(\%)$} \\
\hline Women with documented visits ${ }^{\mathrm{a}}$ & $266(88.1)$ & $240(88.2)$ & $230(88.1)$ & $180(88.7)$ & $164(89.6)$ & $235(100)$ \\
\hline Women with migraine attacks ${ }^{\mathrm{b}}$ & $259(97.4)$ & $177(73.8)$ & $196(85.2)$ & $134(74.4)$ & $119(72.6)$ & $187(79.6)$ \\
\hline \multicolumn{7}{|l|}{ Association with menstruation ${ }^{c}$} \\
\hline No & $165(63.7)$ & $137(77.4)$ & $145(74.0)$ & 93 (69.4) & 88 (73.9) & \\
\hline Yes & $94(36.3)$ & 35 (19.8) & $45(23.0)$ & $40(29.9)$ & $31(26.1)$ & $42(22.5)^{\mathrm{d}}$ \\
\hline
\end{tabular}

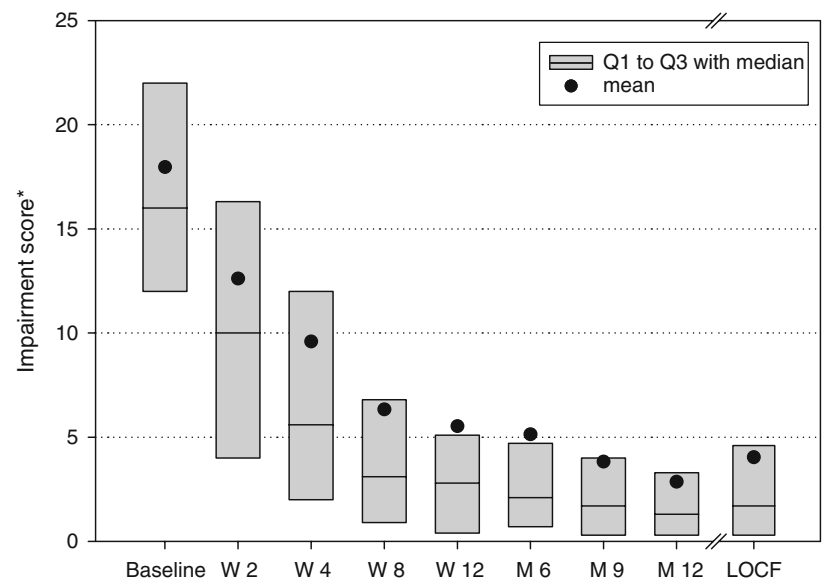

Fig. 5 Impairment of daily life. Asterisk Impairment score $=($ days with severe impairment $\times 3)+($ days with moderate impairment $\times$ $2)+$ (days with slight impairment $\times 1$ )

\section{Quality of life (questionnaire HIT- $6^{T M}$ )}

At baseline, patients started with clinically relevant impairment as measured by HIT- $6^{\mathrm{TM}}$. The sum score changed from $65.2 \pm 4.6$ (median: 65.0, IQR: 63.0-68.0; $N=298$ ) to $51.7 \pm 8.8$ at month 6 (median: 52.0 , IQR: $46.0-58.0 ; N=254$, unknown $N=7$ ), and to $47.5 \pm 8.2$ at month 12 (median: 48.0, IQR: 40.0-54.0; $N=177$, unknown $N=6$ ). The mean LOCF was $48.8 \pm 8.8$ (median: 48.0, IQR: 42.0-56.0; $N=265$ ). The changes from baseline were statistically significant $(p<0.001)$ at all time points and for the ITT population LOCF (Fig. 6).

\section{Therapy satisfaction (tolerability and prophylactic efficacy)}

The physicians assessed tolerability of topiramate as at least "good" in over $90 \%$ of patients (i.e. $97.3 \%$ at month 12). The proportion of patients for whom tolerability was rated "very good" increased during the course of the study:

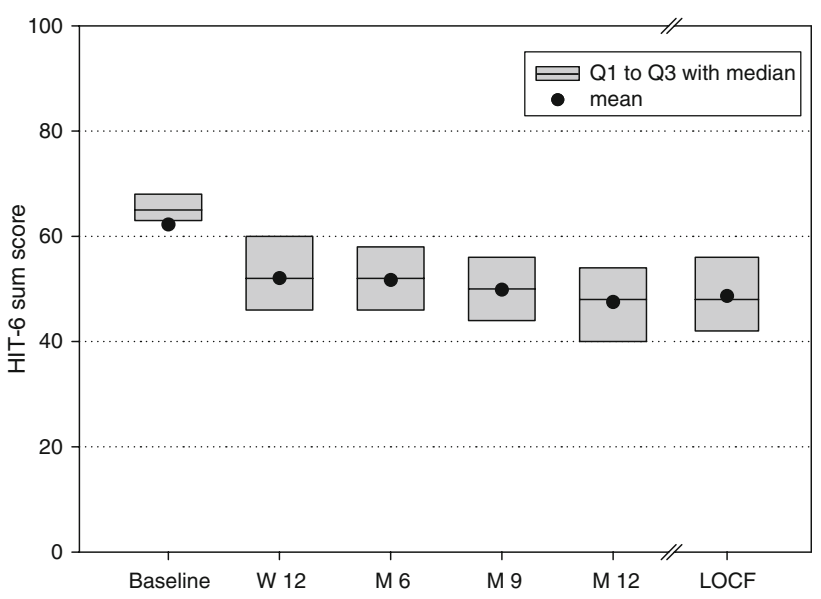

Fig. 6 Quality of life according to the HIT-6 ${ }^{\mathrm{TM}}$ questionnaire

$48.9 \%(N=133)$ at week $12,51.0 \%(N=133)$ at month 6 , and $63.4 \%(N=116)$ at month 12 . Tolerability was considered "not satisfactory" for one patient at week $12(0.4 \%)$ and for one patient at month $12(0.5 \%)$. The LOCF $(N=271)$ yielded very good tolerability for $57.2 \%$, good tolerability for $36.5 \%$, satisfactory tolerability for $5.5 \%$, and not satisfactory tolerability for $0.7 \%$ of patients.

Similarly, the physicians assessed the efficacy outcomes of topiramate as at least "good" in over $85 \%$ of patients ( $86.4 \%$ at week $12,94 \%$ at month 12). Patients' assessment was very similar to the physicians' assessment after 12 weeks of treatment and at the end of the observational period (month 6). The LOCF yielded very good efficacy in $49.8 \%$, good efficacy in $39.1 \%$, satisfactory efficacy in $6.3 \%$, and not satisfactory efficacy in $4.8 \%$ out of 271 patients.

\section{Acute medication}

During the 28 days prior to treatment with topiramate, patients took triptans at $4.9 \pm 3.4$ days (median: 5 days, 
IQR: 3-7 days, $N=289$ ). Other acute migraine medications were taken on average at $9.2 \pm 11.5$ days (median: 5 days, IQR: $3-12$ days, $N=41$ ). During the study, the number of acute treatment days declined. At week 2, the mean number of days with triptan treatment had dropped to $3.8 \pm 4.8$ days (median: 2 days, $N=286$ ) and was further decreased to $1.6 \pm 3.8$ days at month 6 (median: 1 day, $N=254$ ) and to $1.0 \pm 2.6$ days at month 12 (median: 0 days, $N=163$ ). On average, other analgetics were used for $1.3 \pm 3.0$ days at month 6 (median: 0 days; $N=248$ ) and $0.9 \pm 1.1$ days at month 12 (median: 0 days, $N=163$ ), while the mean sum of days of all other acute migraine medications was $3.1 \pm 5.6$ days at month 6 (median: 1 day, $N=49$ ) and $1.4 \pm 0.8$ days at month 12 (median: 1 day, $N=27$ ).

\section{Tolerability}

In the course of the study, 101 AEs were reported in 46 patients (13.7\% of 336 patients) (Table 5). A relationship to treatment with topiramate (possible, or probable, or highly probable) was reported for 64 AEs in 35 patients $(10.4 \%)$ by the treating physician, including two serious AEs (stroke).

One serious adverse event occurred in a 35-year-old obese woman (BMI $30.8 \mathrm{~kg} / \mathrm{m}^{2}$ ) with known menstruationassociated migraines for 10 years who suffered a cerebrovascular accident on 2nd January 2007. Seriousness was based on medical condition as well as hospitalization. At the time of admission, she was treated with topiramate for 12 weeks and experienced improvement in migraine headache frequency as well as associated symptoms. The patient took her last dose the day prior to her insult. The patient had a history of radiation and chemotherapy for Hodgkińs disease in 1989. Based on the physician's

Table 5 Summary of adverse events

\begin{tabular}{ll}
\hline & All patients $N(\%)$ \\
\hline $\begin{array}{l}\text { Number of patients treated } \\
\text { All adverse events }\end{array}$ & 336 \\
Number of adverse events & 101 \\
Patients with adverse events & $46(13.7)$ \\
Patients with serious adverse events & $2(0.6)$ \\
Number of deaths & $0(0.0)$ \\
Related adverse events & \\
Number of adverse events & 64 \\
Patients with adverse events & $35(10.4)$ \\
Patients with serious adverse events & $1(0.3)$ \\
Number of deaths & $0(0.0)$ \\
\hline
\end{tabular}

Percentages relate to patients dosed

Related $=$ possible + probable + likely relationship with topiramate
Table 6 Number of patients with reported adverse events (AEs) during the whole study (safety-sample)

\begin{tabular}{|c|c|c|c|c|}
\hline & \multicolumn{4}{|c|}{ Total } \\
\hline & \multicolumn{2}{|c|}{ All AEs } & \multicolumn{2}{|c|}{ AEs with $\mathrm{CR}^{\mathrm{a}}$} \\
\hline & $N$ & $\%$ & $N$ & $\%$ \\
\hline At least one $\mathrm{AE}^{\mathrm{b}}$ & 46 & 13.7 & 35 & 10.4 \\
\hline \multicolumn{5}{|c|}{ At least one $\mathrm{AE}$ from the following class ${ }^{\mathrm{b}}$} \\
\hline Paraesthesia & 10 & 3.0 & 9 & 2.7 \\
\hline Dizziness & 4 & 1.2 & 4 & 1.2 \\
\hline Diarrhea & 5 & 1.5 & 4 & 1.2 \\
\hline Nausea & 14 & 4.2 & 8 & 2.4 \\
\hline Fatigue & 4 & 1.2 & 4 & 1.2 \\
\hline Vomiting & 4 & 1.2 & 1 & 0.3 \\
\hline
\end{tabular}

Listed are adverse events occurring in $>3$ patients in the total sample

a AEs with possible, probable, or very probable causal relationship (CR) with topiramate as assessed by the investigator

b Multiple events possible

assessment, the SAE was considered as being "possibly" related to topiramate therapy. No further cardio-vascular risk factors were identified. The patient had not fully recovered at the time of the conclusion of the study report. She has been discharged to a rehabilitation center.

The second patient was a 52-year-old woman with a history of episodic migraine for the last 20 years who presented with weight loss. Subsequently, the patient was diagnosed with pituitary insufficiency secondary to a craniopharyngeoma and underwent microsurgical removal. The relationship to topiramate therapy was rated as unlikely. No deaths occurred during the study.

As shown in Table 6, the most frequently reported symptoms were nausea (total: $N=14,4.2 \%$; related: $N=8,2.4 \%$ ), paresthesia (total: $N=10,3.0 \%$; related: $N=9,2.7 \%)$, and vomiting $(N=4,1.2 \%)$. Adverse events reported only in few patients were: fatigue (total and related: $N=4,1.2 \%$ ), diarrhea (total: $N=5,1.5 \%$, related: $N=4,1.2 \%$ ), and dizziness (total and related: $N=4$, $1.2 \%)$. All other symptoms were reported by $<3$ patients.

The mean weight of the patients was stable in the course of the study. At baseline, the mean weight of the 302 patients was $68.6 \pm 11.3 \mathrm{~kg}$ (median: $67 \mathrm{~kg}$, IQR range 60-75 kg). At the end of the follow-up period (month 12) the mean weight of the remaining 183 patients was $68.1 \pm 10.5 \mathrm{~kg}$ (median: $68 \mathrm{~kg}$, IQR: $60-74 \mathrm{~kg}$ ).

\section{Discussion}

In this open label study, tolerability and efficacy outcomes of topiramate for preventive migraine therapy were explored in 336 patients seen in private practices or 
ambulatory care centers. These practitioners are important for successful management of the majority of migraine patients who do not require pain management in a tertiary care center. Both, tolerability and efficacy results in this setting compare well to published data of controlled and open label trials conducted in specialized academic institutions [12, 13, 23, 24].

In 35 patients (10.4\%), at least one treatment-related $\mathrm{AE}$ were reported. The most frequent $\mathrm{AE}$ was paresthesia in 10 patients $(3.0 \%)$. In previous controlled trials, paresthesia was also the most common topiramate-associated $\mathrm{AE}$ (35\%, $51 \%$, and $49 \%$ of patients receiving topiramate $50 \mathrm{mg} /$ day, $100 \mathrm{mg} /$ day, or $200 \mathrm{mg} /$ day, respectively [6\% on placebo]), and thus, higher compared to this study [13, $24,25]$. Incidence of paresthesias in patients treated with topiramate, however, vary considerably across studies with generally lower frequencies in open-label compared to controlled studies. In a recent open label study of topirmate in epilepsy patients, paresthesia was observed in $8.0 \%$ of patients [26]. The other important AE of this study was nausea (4.2\%). All other symptoms of AEs (Table 6), such as fatigue $(1.2 \%)$, dizziness $(1.2 \%)$, impaired attention $(0.9 \%)$, anorexia $(0.9 \%)$, and weight loss $(0.6 \%)$ occurred less frequently. In a pooled analysis of randomized controlled trials, similar frequencies were observed for nausea (8.9\%), fatigue (11.8\%), dizziness (9.7\%), and weight loss $(1.3 \%)$. Topiramate-associated AEs are mild or moderate in severity and occur at consistently higher rates during the titration period compared to the maintenance period of the double-blind phase. Paresthesia, nausea fatigue, and dizziness were also commonly reported AEs in a recent large open label study of topiramate in migraine prevention [21]. The discontinuation rate during the 6 months core phase due to AEs was low. Overall, $77.7 \%$ of all patients completed the 6 months core phase. Among 75 patients who discontinued prematurely (22.3\% of SAF), 7 patients $(2.1 \%)$ had AEs. The most frequent symptoms in these patients were fatigue and nausea, each reported for two patients, respectively. In almost $75 \%$ of patients the reason for discontinuation is unknown and no further information was obtainable. Even if all of these patients discontinued due to adverse events, the effectiveness and retention on treatment compares well to other open label studies and provides additional support for the ease of use and tolerability of topiramate in daily routine for migraine prevention.

As much as 183 patients ( $54.5 \%$ of SAF) completed the full 12-months observation and follow-up period) including Visit 8. Treatment discontinuation due to $\mathrm{AE}$ in previous controlled studies with topiramate was higher, likely due to higher doses in those studies as well as fixed titration schedule [25]. AE-related drop-outs were dose-dependent in all randomized controlled trials [25, 27].
The lower incidence of commonly reported AE's with topiramate and AE-related discontinuation rate of this study is likely due to the lower average daily dose of $57.8 \mathrm{mg}$ topiramate in this study as well as the individualized treatment approach. The 6 months follow up period was optional and reasons for treatment continuation were not formally assessed. The study was conducted at a time when several treatment guidelines recommended discontinuation of preventive therapy after 3-6 months [28]. This has to be contrasted to clinical practice. In some patients, longer treatment continuation might be beneficial. A recently published double-blind placebo controlled study supports this view by showing continued benefit of therapy for 6 months to up to one year [12]. Recently published data even suggest that approximately $50 \%$ of patients might actually benefit from migraine prevention for more than one year [29]. The number of patients who might qualify for a diagnosis of chronic migraine was low, therefore, a subanalyses of treatment response in this patient group was not performed. Recent data suggest that topiramate is effective in chronic migraine treatment [41].

The study population was predominantly female $(87 \%$, $\mathrm{SAF})$. Based on epidemiological data, a higher proportion of men would be expected $[2,30]$. An explanation might be the lower rate of diagnosis in men compared to women which is suggested by the American migraine study. Though close to $50 \%$ of affected individuals are diagnosed, the proportion of men with a diagnosis reaches only $30 \%$ [31]. In addition, as shown in the American migraine prevalence and prevention study, current or ever use of preventive medication was more likely in women than in men (odds ratio $[\mathrm{OR}]=1.37,95 \%$ confidence interval $[\mathrm{CI}]$ 1.27-1.48), increased with age and individuals with high MIDAS grade (Grade IV vs. I, OR 2.35, 95\% CI 2.092.64) [32]. In addition, a higher rate of vocational activity among men may result in limited interest to participate in an open label study resulting in an artificially low number of participants. Post-hoc analyses based on the pivotal trials do not suggest a differential response in women or men as another possible explanation [24].

After 6 months of treatment, patients receiving topiramate had less than one migraine attack per month. The median number of migraine attacks declined from 4.0 to 0.9. The preventive treatment effect was maintained throughout the follow-up phase. The number of migraine days per month was also significantly reduced. Treatment with topiramate was also associated with significant improvements for several other migraine treatment effect measures, such as pain intensity and consumption of analgesics. At the end of the 6 months core phase, the frequency of migraine attacks could be reduced by at least $50 \%$ compared to baseline for $76 \%$ of patients. The proportion of patients with more than $50 \%$ migraine reduction 
reached $80 \%$ during the follow-up period. As much as $21 \%$ of all patients were completely free of migraine attacks at the end of the follow-up phase.

The efficacy data of this study are comparable with those of randomized controlled trials. Brandes reported a $40 \%$ reduction in migraine frequency for daily doses of $100 \mathrm{mg}$ and a $42 \%$ reduction for daily doses of $200 \mathrm{mg}$ at 6 months endpoint [25]. Similar reduction rates were also observed in other controlled trials [13]. Results from these placebo-controlled trials, however, suggest that even total daily doses at $50 \mathrm{mg}$ might have a significant effect compared to placebo or show at least incremental benefit. In this study, topiramate was dosed between 25 and $200 \mathrm{mg} /$ day with a mean daily dose of 58.7. $\pm 27.7 \mathrm{mg}$, indicating that reduction of migraine days and pain intensity can be achieved with lower levels of topiramate.

Menstrual migraine was observed in $36 \%$ of female migraineurs which is lower than the $50 \%$ expected based on epidemiological data [33]. In this subgroup of women in our study, a clinically relevant reduction of migraine attacks after 6 months was observed. Compared to nonmenstrual migraine, menstrual migraine attacks are often more severe, longer in duration, and have a poorer response to analgesics. Epidemiological, pathophysiological, and clinical evidences link estrogen to migraine headaches [34, 35]. For the preventive treatment of menstrual migraine, there are grade B recommendations for the perimenstrual use of transcutaneous estrogen $1.5 \mathrm{mg}$. Also, frovatriptan $2.5 \mathrm{mg}$ twice daily and naratriptan $1 \mathrm{mg}$ twice daily have shown efficacy in prevention of menstrual migraine [22]. None of these agents was used in our patients. Even considering the limitations of this study by not having defined menstruation-related migraines according to the international headache society criteria [22], these data may suggest that menstrual migraine attacks respond to preventive treatment with topiramate. A post-hoc analyses based on a recently published trial is supportive of this view [12].

We also observed significant improvement on measurements of daily living activities and health related quality of life. In the course of the 12-month study period, the median impairment score decreased from 16.0 to 1.3 points and the HIT- $6^{\mathrm{TM}}$ score sum decreased from 65.0 to 48.0 points. The improvement of functional outcome with topiramate migraine prophylaxis is exemplified by the reduction of days absent from work (from a median of 2.0 days per month at baseline to 0.0 days after treatment). Similar observations have been reported from other studies using health-related quality of life endpoints, such as Migraine Specific Questionnaire (MSQ) and the Medical Outcomes Study 36-item Short-Form Health Survey (SF-36) [36]. In a 3-month prospective study of 103 migraine patients, for example, all SF-36 items improved after patients were started on pharmacologic migraine prophylaxis [37].
Improved health-related quality of life outcome and vocational activities are prime objectives of preventive migraine therapy. Preventive therapy with topiramate was shown to be associated with significant decreases in resource use based on pharmacy data claim analyses [9] as well as an increased work place productivity based on results of randomized controlled trials [38].

The observed treatment effects of an open label study need to be interpreted with caution. Several controlled studies have demonstrated a powerful placebo-effect in migraine prevention [39]. In one meta-analysis of all placebo-controlled studies of propranolol for prevention of migraine, the response rate for propranolol was $55.1 \%$ and for placebo $14.3 \%$ [40]. A very recent meta-analysis reported placebo responder rates of $21 \%$. In the current study, the extent of reduction in migraine attacks, migraine days, maximum pain intensity, and consumption of analgesics, however, is comparable to responder rates of active substances in controlled studies. Therefore, the improved migraine control observed in this study cannot be attributed to a placebo effect alone.

The results of the current study further support that topiramate is generally well tolerated and effective in migraine prevention when administered by non-specialized physicians. Topiramate showed significant reduction in the frequency of migraine attacks, migraine days, pain intensity, and improvement on health-related quality of life outcomes. These results may spur the effort to improve the current underutilization of pharmacologic migraine prevention outside tertiary or specialized care.

Acknowledgments We thank the study coordinators from JanssenCilag, Germany for their contribution and Kerstin Schuppien and Tanja Hendrichs, $\mathrm{PhD}$, for editorial assistance with the manuscript.

Conflict of interest Dr. Bornhoevd and Dr. Schauble are full time employees of Janssen-Cilag EMEA, Neuss, Germany. The study was conducted by Medidata, Konstanz, Germany and Dr. Fritzsche served as a consultant for the statistical analysis. The study has been sponsored by Janssen-Cilag Germany.

\section{Appendix}

We gratefully acknowledge the participation of following TOPMAT-MIG-0001 investigators: Thomas Wegner, Königstein; Hans Werner Fischer, Friedrichsthal; Bernhard Wolfram, Mannheim; Karin Schindlbeck, Parsberg; Susanne Peters, Dortmund; Ursula Schax, Essen; Eva M. Dietz, Bamberg; Juergen Haas, Nürnberg; Markus Föh, Fulda; D. Katholnigg, Mönchengladbach; Gerd Rauch, Bayreuth; Martin Kühn, München; Veit-Ulrich Becker, Hamburg; Michael Springer, Pirmasens; Guido M. Auner, Lüdenscheid; Kristin Hontzek, Dommitzsch; Heinz-Wilhelm 
Kaune, Lohfelden; Volker Schreibmüller, Barsinghausen; Svetlana Liadski, Essen; B. Wiedeking, Essen; Michael Rengeling, Petershagen; Volker Henning, Oberdorla; Barbara Walaschewski, Grabowhöfe; Roland J. Schätzl, Großheirath; Barbara Steinbrück, Stuttgart; Henner Reineke, Stuttgart; Sven Rönnebeck, Hedersleben; Tobias Armbruster, Heilbronn; Roland J. Schätzl, Ebersdorf; Anke Tiedt, Claußnitz; Tim Hördt, Bielefeld; Frank Eisenkrätzer, Radebeul; Rainer Waldmann, Stuttgart; Petra Sandow, Berlin; Bernd Metzger, Stuttgart; Anja Eckert, Leipzig; Nader Kayali, Dorsten; Michael Lang, Ulm; Harald Klein, Darmstadt; Hilmar Böneke, Lienen; Christoph Schiel, Giessen; Matthias Eyck, Berlin; Hans-Dieter Gross, Limburg; Andreas Beck, München; Bernd Spengruber, Wangen im Allgäu; Markus Schulz-Meentzen, Bremen; Arnulf Gruber, Brensbach; Andrea Rubbel-Ehle, Niebuell; Bernd Porrmann, Baden-Baden; Marius Unger, Giengen an der Brenz; Klaus-Peter W. Schaps, Wilhelmshaven; Helmut Stienker-Fisse, Remscheid; Gabriele Meyer, Berlin; Alexander Matuschke, Weyhe; Heike Eckardt, Gütersloh; Ursula Jansen, Pulheim; Katy Klook, Rostock; Mirko Witteborn, Halberstadt; Theresia Roidl, Schwandorf; Katharina Farke-Rämer, Berlin; Michael Dietlein, Augsburg; Peter Möller, Marl; Winfried Hofmann, Marburg; Suso Lederle, Stuttgart; Frank Wiedemann, Kandern-Wollbach; Ursula Rieser, Bärnau; Martin L.J. Wimmer, München; Christa Enderle, Riedlingen; Detlef Gottesbüren, S.gmünd; Thomas Weber, Haren; Manfred Oberling, Bad Camberg; Werner Flöhl, Paderborn; Nenad Martinovic, Eheine; Wolfgang Köller, Berlin; Bärbel Jersch, Schönebeck; Heidrun Adam, Rostock; Olaf Carstensen, Eckernförde; Kerstin Franke, Berlin; Norbert Martini, Gechingen; Hildegard Schneider-Nutz, Köln; Eberhard Bek, Langenbrettach; Birgit Magnus-Ellenbroek, Emmerich: Borries Kukowski, Göttingen; Uwe Jorns, Trossingen; Tatjana Kelch, Dresden; Günther Endrass, Grünstadt; Rainer Katzfuss, Sommerhausen; Lukas Schmitt, Hamburg; Frank Kühn, Oranienburg; Hanns-Joachim Schietsch, Augsburg; Hans D. Diery, Butzbach; Doris Wiese-Junginger, Planegg; Freia Guse-Grosse, Jülich; Jens Thonack, Greifswald; Peter Franz, Berlin; Regina Dauwe, Ettlingen; Uwe Gerbaulet, Löhne; Sabine Koller, Saerbeck; Eva Freitag, Berlin; Reinhard Krug, Ulm; Berthold Jonas, Essen; Alfons Linke, Tübingen; Achim Ulmer, Ludwigsburg; Sigmund Jakob, Weinsberg; Volker Gillwald, Mönchengladbach; Mario Tomm, Heek; Nikolaos Ampatziadis, Wiesbaden; Josip Udosic, München; Christa Koßler-Wiesweg, Essen; KnutOlaf Brose, Syke; Hans-Peter Westfal, Göttingen; Radu Dan Noveanu, Leonberg; Cornelia Jacob, Lippersdorf; Vilém Fuchs, Köln; Axel Althen, Hainburg; Andreas Lang, Wilhelmshaven; Rupert Lebmeier, Zweibrücken; Karl Friedrich Beykirch, Frankfurt; Steve Müller, Güglingen; Gerhard Krehan, Graben-Neudorf; Robert Ivancic,
Gersthofen; Andrea Eichhorn, Wadgassen; Felix Lion, Volkmarsen; Arkadius Misera; Düsseldorf; Christian Nowack, Durmersheim; Andre Wagner, Teutschenthal; Manfred Böger, Castrop-Rauxel; Stefan Ries, Erbach; Klaus Hachenberg, Gütersloh; Peter Pickert, Frankfurt; Marianne Lang, Neckargemünd; Volker Strick, Köln; Anneliese Lüdtke, Neu-Ulm; Maria Siemer, Haselünne; Sinta Setiawan, Nordhorn; Gabriele Feuerstack, Heikendorf; Axel Müller, Magdeburg; Senta Kim-Giesemann, Friesoythe; D. Noack, Limburgerhof; Barbara Unsorg, Erbach; Rainer Busch, Münchweiler; Klaus Weischer, Rheine; Christoph Stenzel, Köln; Christian Albrecht, Hasbergen; Ulrich Assmann, Weil am Rhein; Maria Wegner, Viernheim; Holger Hufnagel, Neckarbischofsheim; Marco Loddo, Rastede; Lutz-Dieter Lohse, Dresden; Wolfgang Derissen, Mönchengladbach; Bernd Junge, Uttenreuth; Frank Seidel, Wiefelstede; Harald Bannies, Solingen; Imke Hanoldt, Stolberg; Rainer Bachus, Berlin; Eva Burger-Deinerth, Berlin; Hoang Ha-Phuoc, Olpe; Memet Gülbeyaz, Hamburg; Gunter Brauer, Cottbus; Wolfgang Leps, Berlin; Faizurrahman Ahrari, Hamburg; Stephan Lode, Hückeswagen; Christian Brandt, Gronau; Rolf Zimmermann, Dessau; Andreas Böhme, Delitzsch; Markus BruckhausWalter, Herne; Udo Phillipp, Berlin; Ulrich Loel, Salzgitter; Michael Bruch, Herne; Kerstin Schulze, Norderstedt; Steffen Christian Kohl, Dessau; Reinhard Lakony, Berlin; Marion Nesimi, Wildau; Hans-Dieter Zug, Böblingen; Serena Scarel, Unterhaching; Ulrich G. Schultheiß, Sigmaringen; Sibylle Berdermann-Welz, Altenburg; Walter Freudenstein, Braunschweig; Regine Schmitt, Nußbach; Angelika Christopher, Berlin; Uwe Patzelt, Seelow; Doris Augustin-Reuss, Solingen; Karl-Otto Sigel, Unterhaching.

\section{References}

1. Bigal ME, Lipton RB (2009) The epidemiology, burden, and comorbidities of migraine. Neurol Clin 27:321-334

2. Jensen R, Stovner LJ (2008) Epidemiology and comorbidity of headache. Lancet Neurol 7:354-361

3. Lipton RB, Bigal ME, Diamond M, Freitag F, Reed ML, Stewart WF (2007) Migraine prevalence, disease burden, and the need for preventive therapy. Neurology 68:343-349

4. Lipton RB, Bigal ME (2005) The epidemiology of migraine. Am J Med 118(Suppl 1):3S-10S

5. Halpern MT, Lipton RB, Cady RK, Kwong WJ, Marlo KO, Batenhorst AS (2002) Costs and outcomes of early versus delayed migraine treatment with sumatriptan. Headache 42:984-999

6. Hu XH, Markson LE, Lipton RB, Stewart WF, Berger ML (1999) Burden of migraine in the United States: disability and economic costs. Arch Intern Med 159:813-818

7. Buse DC, Rupnow MF, Lipton RB (2009) Assessing and managing all aspects of migraine: migraine attacks, migraine-related functional impairment, common comorbidities, and quality of life. Mayo Clin Proc 84:422-435 
8. Silberstein SD, Goadsby PJ, Lipton RB (2000) Management of migraine: an algorithmic approach. Neurology 55:S46-S52

9. Silberstein SD, Feliu AL, Rupnow MF, Blount AC, Boccuzzi SJ (2007) Topiramate in migraine prophylaxis: long-term impact on resource utilization and cost. Headache 47:500-510

10. Diener HC, Brune K, Gerber WD, Pfaffenrath V, Straube A (2000) Therapy of the acute migraine attack and migraine prophylaxis. Recommendation of the "Deutsche Migrane- und Kopfschmerz-Gesellschaft. Schmerz 14:269-283

11. Dodick DW, Freitag F, Banks J, Saper J, Xiang J, Rupnow M, Biondi D, Greenberg SJ, Hulihan J (2009) Topiramate versus amitriptyline in migraine prevention: a 26-week, multicenter, randomized, double-blind, double-dummy, parallel-group noninferiority trial in adult migraineurs. Clin Ther 31:542-559

12. Diener HC, Agosti R, Allais G, Bergmans P, Bussone G, Davies B, Ertas M, Lanteri-Minet M, Reuter U, Del Rio MS, Schoenen J, Schwalen S, van Oene OJ (2007) Cessation versus continuation of 6-month migraine preventive therapy with topiramate (PROMPT): a randomised, double-blind, placebo-controlled trial. Lancet Neurol 6:1054-1062

13. Diener HC, Tfelt-Hansen P, Dahlof C, Lainez MJ, Sandrini G, Wang SJ, Neto W, Vijapurkar U, Doyle A, Jacobs D (2004) Topiramate in migraine prophylaxis-results from a placebo-controlled trial with propranolol as an active control. J Neurol 251:943-950

14. Diener HC, Matias-Guiu J, Hartung E, Pfaffenrath V, Ludin HP, Nappi G, De Beukelaar F (2002) Efficacy and tolerability in migraine prophylaxis of flunarizine in reduced doses: a comparison with propranolol $160 \mathrm{mg}$ daily. Cephalalgia 22:209-221

15. Silberstein SD (2004) Topiramate in migraine prevention: evidence-based medicine from clinical trials. Neurol Sci 25(Suppl 3): S244-S245

16. Mathew NT, Saper JR, Silberstein SD, Rankin L, Markley HG, Solomon S, Rapoport AM, Silber CJ, Deaton RL (1995) Migraine prophylaxis with divalproex. Arch Neurol 52:281-286

17. Pascual J, Leira R, Lainez JM (2003) Combined therapy for migraine prevention? Clinical experience with a beta-blocker plus sodium valproate in 52 resistant migraine patients. Cephalalgia 23:961-962

18. Silberstein SD, Hulihan J, Karim MR, Wu SC, Jordan D, Karvois D, Kamin M (2006) Efficacy and tolerability of topiramate $200 \mathrm{mg} / \mathrm{d}$ in the prevention of migraine with/without aura in adults: a randomized, placebo-controlled, double-blind, 12-week pilot study. Clin Ther 28:1002-1011

19. Brandes JL (2002) Global trends in migraine care: results from the MAZE survey. CNS Drugs 16(Suppl 1):13-18

20. Lanteri-Minet M (2008) The role of general practitioners in migraine management. Cephalalgia 28(Suppl 2):1-8

21. Nelles G, Delbrück A, Schulze 1, Kademann B, Bornhoevd K, Schäfer S, Schauble B (2009) Topiramate for migraine prevention in a naturalistic setting-results from an open label, flexible dose study. Headache [Epub ahead of print]

22. Pringsheim T, Davenport WJ, Dodick D (2008) Acute treatment and prevention of menstrually related migraine headache: evidence-based review. Neurology 70:1555-1563

23. Rapoport A, Mauskop A, Diener HC, Schwalen S, Pfeil J (2006) Long-term migraine prevention with topiramate: open-label extension of pivotal trials. Headache 46:1151-1160

24. Bussone G, Diener HC, Pfeil J, Schwalen S (2005) Topiramate $100 \mathrm{mg} /$ day in migraine prevention: a pooled analysis of doubleblind randomised controlled trials. Int J Clin Pract 59:961-968
25. Brandes JL, Saper JR, Diamond M, Couch JR, Lewis DW, Schmitt J, Neto W, Schwabe S, Jacobs D (2004) Topiramate for migraine prevention: a randomized controlled trial. JAMA 291:965-973

26. Kurth C, Schauble B, Schreiner A, Rettig K, Steinhoff BJ (2009) Exploring efficacy and tolerability outcomes in patients with difficult-to-treat epilepsy receiving adjunctive topiramate at different titration rates-an exploratory study. Acta Neurol Scand 120:80-87

27. Silberstein SD, Neto W, Schmitt J, Jacobs D (2004) Topiramate in migraine prevention: results of a large controlled trial. Arch Neurol 61:490-495

28. Treatment Guideline Subcommittee of the Taiwan Headache Society (2008) Treatment guidelines for preventive treatment of migraine. Acta Neurol Taiwan 17:132-148

29. Pascual J, El BY, Gomez-Sanchez JC (2007) How many migraine patients need prolonged ( $>1$ year) preventive treatment? Experience with topiramate. J Headache Pain 8:90-93

30. Lipton RB, Stewart WF, Diamond S, Diamond ML, Reed M (2001) Prevalence and burden of migraine in the United States: data from the American Migraine Study II. Headache 41:646-657

31. Lipton RB, Diamond S, Reed M, Diamond ML, Stewart WF (2001) Migraine diagnosis and treatment: results from the American Migraine Study II. Headache 41:638-645

32. Diamond S, Bigal ME, Silberstein S, Loder E, Reed M, Lipton RB (2007) Patterns of diagnosis and acute and preventive treatment for migraine in the United States: results from the American Migraine Prevalence and Prevention study. Headache 47:355-363

33. Martin VT, Lipton RB (2008) Epidemiology and biology of menstrual migraine. Headache 48(Suppl 3):S124-S130

34. MacGregor EA (1997) Menstruation, sex hormones, and migraine. Neurol Clin 15:125-141

35. MacGregor EA (1996) "Menstrual" migraine: towards a definition. Cephalalgia 16:11-21

36. Brandes JL, Kudrow DB, Rothrock JF, Rupnow MF, Fairclough DL, Greenberg SJ (2006) Assessing the ability of topiramate to improve the daily activities of patients with migraine. Mayo Clin Proc 81:1311-1319

37. D'Amico D, Lanteri-Minet M (2006) Migraine preventive therapy: selection of appropriate patients and general principles of management. Expert Rev Neurother 6:1147-1157

38. Lofland JH, Gagne JJ, Pizzi LT, Rupnow M, Silberstein SD (2007) Impact of topiramate migraine prophylaxis on workplace productivity: results from two US randomized, double-blind, placebo-controlled, multicenter trials. J Occup Environ Med 49:252-257

39. Diener HC, Schorn CF, Bingel U, Dodick DW (2008) The importance of placebo in headache research. Cephalalgia 28:1003-1011

40. Holroyd KA, Penzien DB, Cordingley GE (1991) Propranolol in the management of recurrent migraine: a meta-analytic review. Headache 31:333-340

41. Diener HC, Dodick DW, Goadsby PJ, Bigal ME, Bussone G, Silberstein SD, Mathew N, Ascher S, Morein J, Hulihan JF, Biondi DM, Greenberg SJ (2009) Utility of topiramate for the treatment of patients with chronic migraine in the presence or absence of acute medication overuse. Cephalalgia 29(10):1021-1027 